\title{
$\mathrm{T}_{\mathrm{HE}} \mathbf{A}_{\mathrm{sL}} \boldsymbol{P}_{\mathrm{ACHFC}} \boldsymbol{S}_{\mathrm{CHOLAR}}$ \\ MEDICAL AND HEALTH PROFESSIONS EDUCATION
}

CASE STUDY

Published online: 7 May, TAPS 2019, 4(2), 58-60

DOI: https://doi.org/10.29060/TAPS.2019-4-2/CS2046

\section{Our journey through the Medical Grand Challenge 2017}

\author{
Wenqi Chiew ${ }^{1}$, Zi Qiang Glen Liau², Wen Guang Benson Ang ${ }^{1}$, Jolyn Moh $^{3}$ \& \\ Wilson Wang ${ }^{1,2}$
}

${ }^{1}$ Yong Loo Lin School of Medicine, National University of Singapore, Singapore; 'Department of Orthopaedic Surgery, National University Hospital, Singapore; ${ }^{3}$ NUS Business School, National University of Singapore, Singapore

\section{INTRODUCTION}

Medical Grand Challenge (MGC) 2017 was the inaugural student-led medical innovation competition hosted by the Yong Loo Lin School of Medicine (YLLSOM) in National University of Singapore (NUS) which provided a platform for students from different faculties to come together to brainstorm for innovative solutions to real healthcare problems.

MGC was started with the intention of providing more opportunities for inter-faculty collaboration and medical innovation in the local healthcare scene. Collaboration and innovation are key concepts that can be used in patient-centred care to improve services and outcomes for patients (D'Amour, Ferrada-Videla, Rodriguez, \& Beaulieu, 2005; Davis \& Marshall, 2014). MGC supplements the medical education curriculum by enabling students to view opportunities in healthcare problems and equip them with the necessary knowledge, skills and familiarity with possible resources to tackle similar challenges in future.

\section{METHODS}

The requirement for team composition was to have at least one medical student and any number of students from at least two other faculties. The shortlisted teams were provided with a $\$ \$ 500$ seed grant and the option to look for mentors to guide them. Participation in the competition was not exclusive to teams that receive the grants but were also open to all other teams that met the requirements. Initial marketing efforts such as email broadcasts to all NUS students and posters were placed around NUS to increase awareness and participation in MGC.

\begin{tabular}{|c|c|c|c|c|c|}
\hline $\begin{array}{l}1^{\text {st }} \text { month } \\
\text { (August 2016) }\end{array}$ & $2^{\text {nd }}$ month & $8^{\text {th }}$ month & $9^{\text {th }}$ month & $\begin{array}{l}10^{\text {th }}-11^{\text {th }} \\
\text { month }\end{array}$ & $13^{\text {th }}$ month \\
\hline $\begin{array}{l}\text { Interaction } \\
\text { event and } 2 \\
\text { Bootcamps }\end{array}$ & $\begin{array}{l}\text { Idea } \\
\text { Submission }\end{array}$ & $\begin{array}{l}\text { First } \\
\text { Workshop }\end{array}$ & $\begin{array}{l}\text { Midterm } \\
\text { Review }\end{array}$ & $\begin{array}{l}\text { Visits to } \\
\text { healthcare firms } \\
\text { and subsequent } 4 \\
\text { workshops }\end{array}$ & $\begin{array}{l}\text { Final submission } \\
\text { and finale night }\end{array}$ \\
\hline
\end{tabular}

Figure 1. The sequence of events of MGC

The timeline of MGC is shown in figure 1. The year-long program kick-started with an interaction event and two boot camps in early August 2016 for students from different faculties to mingle and form teams. This was 
followed by the submission of an idea. The ideas were scrutinised by two judges from the NUS teaching faculty and the approved ideas were then allocated the grants to start their projects.

From the eighth to eleventh month, five workshops were conducted by invited speakers regarding the following topics:

1. Design process and systems thinking;

2. Intellectual property;

3. Cost-benefit analysis;

4. Ethical considerations for health interventions and regulatory strategy; and

5. Pitching and presentation.

There were also opportunities for visits to a wide range of healthcare firms such as Jaga-Me (local startup), SGInnovate (government-owned firm) and Medtronic (multinational company) with the purpose of increasing students' exposure to medical innovation.

A total of two submissions were required and graded by two judges - a midterm submission of 1,000 words proposal and a final submission consisting of 1,500 words proposal, a three-minute marketing video and a poster.

The finale night comprised of a 6-minute poster presentation by all teams. Subsequently, the top 6 teams chosen from the poster presentation gave a 6-minute oral presentation to compete for the top 3 prizes. The judging criteria were weighted on healthcare impact (30\%), innovation novelty $(30 \%)$, collaboration $(10 \%)$, viability, marketing and business model (30\%).

\section{RESULTS}

Out of 34 teams who submitted, 19 teams were shortlisted for the finale night, including our team. We developed a prototype of a mobile phone application named "MissiQ" that aimed to improve patients' outpatient clinic experience. The all-encompassing application conveniently allows patients to view all their appointments and medications, to register online, view a live update of the waiting time and access an automated chatbot that responds to queries. Although we did not place first, there was great public interest in our project and we were interviewed by a local newspaper - The New Paper as part of the article "NUS students develop apps to help patients" published on 21 August 2017.

The 1st prize went to Team Hipportable who invented a harness to facilitate nurses to transfer bed-bound patients. The 2nd prize went to Team PD Safe who The Asia Pacific Scholar, Vol. 4 No. 2 / May 2019 Copyright $(2) 2019$ TAPS. All rights reserved. invented a device to sanitise dialysis tube connections using UV light. The 3rd prize went to Team Foot Sense who invented a foot pad to detect temperature changes in the feet which may indicate an impending ulcer, especially in diabetics. As of April 2018, the top 2 teams are in the midst of filing for patents.

\section{DISCUSSION}

The concept of incorporating medical innovation into education is not new. The University of Utah started their medical innovation competition "Bench to Bedside" in 2010 with the aim of training a new generation of clinician-innovators (Loftus, Elder, D'Ambrosio, \& Langell, 2015). Since then, the competition has led to 145 innovations, 107 patents and launched 38 companies (Lovell, 2016).

This MGC journey allowed students to dream big and aim for the impossible and encourages students to begin the first step of building a solution that could potentially benefit many in the future. Through this experience, lasting friendships were built and knowledge from different fields was gained. Author Wenqi, a medical student, attended coding workshops and found a new interest in medical technology and engineering. Author Benson, also a medical student, learned more about coding, business and marketing strategies and re-ignited a passion for financial analysis. Author Jolyn, a Business student, learned that in today's digital age, technology serves as a good tool to catalyse development as a country and while it is always important to dream big, it is even more pertinent to start small, then scale up. Author and Mentor Dr Glen, an Orthopaedic resident, had an enjoyable experience melding the domains of medicine, innovation and business in the tutelage of the group.

Despite the advantages and potentials of $\mathrm{MGC}$, the authors acknowledge that the implementation of such a programme requires a substantial amount of funding and administrative support from the school to ensure the success of the programme. As such, it is imperative that the leadership of the school sees the value of student innovation education beyond our textbooks.

The authors believe that it is essential to train a new generation of students to be clinician-innovators that can seek opportunities for innovation where others see difficulties and inefficiencies. To do so, the students will need support to create small but important changes that may ultimately result in greater transformations in healthcare (Zuckerman, Margolis, \& Mate, 2013). 


\section{Notes on Contributors}

Wenqi is a third-year medical student from Yong Loo Lin School of Medicine, National University of Singapore and a holder of the Singapore Armed Forces Medicine scholarship. Apart from medical innovations, her other interests include military medicine, martial arts, soccer and scuba diving.

Dr Glen Liau (MBBS, MRCS, MBA) is an Orthopaedic surgery resident at National University Hospital System. $\mathrm{He}$ is the corresponding author for this paper. His other interests include technological innovations, financial analyses, and macroeconomic discussions to the tune of a good violin concerto.

Benson is a third-year medical student from Yong Loo Lin School of Medicine, National University of Singapore. He has a special interest in clinical reasoning and medical innovation. On top of his medical training, Benson spends his time on financial analysis.

Jolyn is a third-year business student from School of Business, National University of Singapore. She is passionate about the healthcare scene in Singapore where she hopes to leave an impact on people's lives. Her other interests include psychology, entrepreneurship and music.

Associate Professor Wilson Wang (MBBS, FRCS, DPhil) is Head of Orthopaedic Surgery, National University Hospital and Yong Loo Lin School of Medicine, National University of Singapore. His areas of interests in research include research supervision, clinical orthopaedics, biomaterials, bone cell biology, cellular and molecular research techniques.

\section{Acknowledgements}

We would like to thank the organising committee of Medical Grand Challenge for giving us the opportunity to take part in the event.

\section{Funding Statement}

There is no funding for this paper.

\section{Declaration of Interest}

There is no conflict of interest, including financial, institutional or otherwise for any of the authors involved.

\section{References}

D'Amour, D., Ferrada-Videla, M., San Martin Rodriguez, L., \& Beaulieu, M. D. (2005). The conceptual basis for interprofessional collaboration: Core concepts and theoretical frameworks. Journal of Interprofessional Care, 19 Supplementary 1, 116-131. https://doi.org/10.1080/13561820500082529

Davis, P. D., \& Marshall, D. R. (2014). Teamwork: An essential for leading and launching innovation. Nursing Administration Quarterly, 38(3), 221-229.

https://doi.org/10.1097/naq.0000000000000046

Loftus, P. D., Elder, C. T., D'Ambrosio, T., \& Langell, J. T. (2015). Addressing challenges of training a new generation of clinicianinnovators through an interdisciplinary medical technology design program: Bench-to-Bedside. Clinical and Translational Medicine, 4, 15-15. https://doi.org/10.1186/s40169-015-0056-3

Lovell, A. (2016). Bench to Bedside Competition Report. Retrieved from University of Utah Health Sciences, Office of Public Affairs \& Marketing: https://uofuhealth.utah.edu/center-for-medicalinnovation/files/b2b-reports/b2breport_2016.pdf

Zuckerman, B., Margolis, P. A., \& Mate, K. S. (2013). Health services innovation: The time is now. Journal of American Medical Association, 309(11), 1113-1114. https://doi.org/10.1001/jama.2013.2007

\footnotetext{
*Glen Liau

National University Hospital,

Department of Orthopaedic Surgery,

$1 \mathrm{E}$ Kent Ridge Road,

NUHS Tower Block, Level 11,

Singapore 119228

Tel: +65 67795555

Email address: glen_liau@nuhs.edu.sg
} 